The Tang Center for Early China at Columbia University was founded in 2015 through a generous endowment gift from Oscar Tang and Agnes Hsu-Tang. The Tang Center is dedicated to the advancement of the understanding of the richness and importance of early Chinese civilization as a part of a broader common human heritage. It is committed to doing so through both solid scholarship and broad public outreach. The Tang Center sponsors a variety of conferences, workshops as well as public lectures each year including the Columbia Early China Seminar. The Tang Center is especially interested in supporting research initiatives that aim to examine newly discovered paleographic and textual material as well as artifacts, and in promoting the role of archaeology as a path to understand the past.

\title{
Call for Manuscripts
}

\section{Tang Center Series in Early China}

Sponsored by the Tang Center and to be published by Columbia University Press, the "Tang Center Series in Early China" includes new studies that make major contributions to our understanding of early Chinese civilization or that which break new theoretical or methodological grounds in Early China studies. The series is especially interested in publishing works that analyze newly discovered paleographic and manuscript materials as well as archaeological data. Disciplinary focuses of the series are history, archaeology, art history, anthropology, literature, philosophy, and the history of sciences and technology. The series spans from the Neolithic period to the end of the Han Dynasty (AD 220), or to the end of the Tang Dynasty (AD 907) for titles in archaeology. All submissions are subject to peer reviews and editorial evaluation. For more information, please see http://tangcenter-columbia. org/publications/. Interested authors should submit a book proposal (maximum 25 manuscript pages), accompanied by CV, to: info@tangcenter-columbia.org, or by mail to: 509 Kent Hall, 1140 Amsterdam Avenue, MC 3907, Columbia University, New York, NY 10027.

\section{Call for Applications}

The Tang Post-Doctoral Research Award in Early China Studies

The Tang Center for Early China offers one Post-Doctoral Research Award in the amount of $\$ 15,000$ each year in recognition of outstanding research projects in early Chinese civilization or in archaeology.

\section{The Tang Visiting Scholar's Fellowship}

The Tang Center offers Visiting Scholar's Fellowship each year to one scholar for an in-residence research period of 10 months at Columbia University, or to two scholars for a period of 5 months each, depending on the need of the proposed projects. The applicant must be non-US based.

\begin{abstract}
Workshop and Conference Grants
The Tang Center offers grants in the amount of $\$ 13,000$ each to up to two workshop and/or conference proposals each academic year, depending on the scale. Each workshop or conference should have an identified central problem or theme on which the papers will focus. Alternatively, the workshop/ conference can be centered on a newly discovered corpus of materials or manuscripts, or on an important archaeological site, or a region.
\end{abstract}

Application deadline, November 30 , for all programs.

For more information, please visit our website www.tangcenter-columbia.org. Questions directed to: info@tangcenter-columbia.org; or by phone: 212.854.5546. 


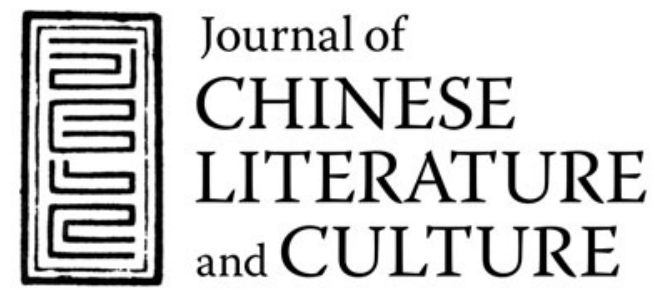

The Journal of Chinese Literature and Culture publishes research articles and essays on premodern Chinese literature and all aspects of the broader literary culture.

Jointly sponsored by Peking University and the University of Illinois, the journal embodies an international editorial vision that brings together scholars in China, the United States, and other parts of the world.

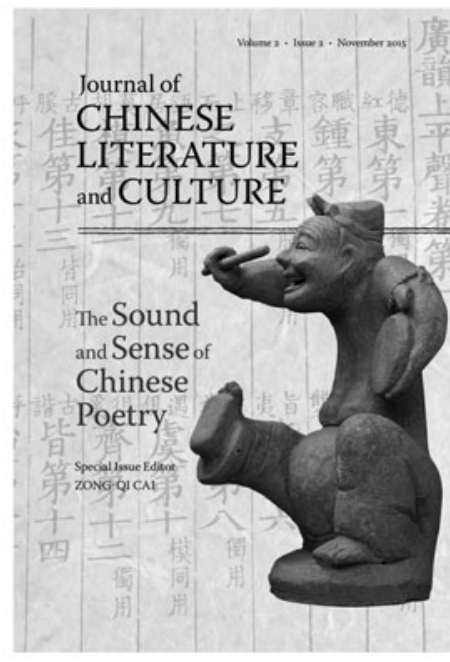

Yuan Xingpei and Zong-qi Cai, editors

Subscribe today!

Two issues annually

Individuals, \$30

Students, $\$ 20$

\section{U K E}

Members of the Forum on Chinese Poetic Culture receive a discount on subscriptions and individual issues. For more information, visit chinesepoetryforum.org.

dukeupress.edu/jclc 888.651.0122 | + 1.919.688.5134 subscriptions@dukeupress.edu 


\section{Area Studies Books and Journals from Cambridge University Press}

Cambridge has a vibrant programme of books and journals spanning all geographical areas of the world.

We publish prestigious book series and standalone titles that analyse regions through a variety of disciplines in both the humanities and social sciences, ranging from politics, economics and history through to anthropology and religion.

Our multi- and interdisciplinary journals regularly achieve high Impact Factors and lead their respective fields.

For further details visit:

cambridge.org/core-areastudies 


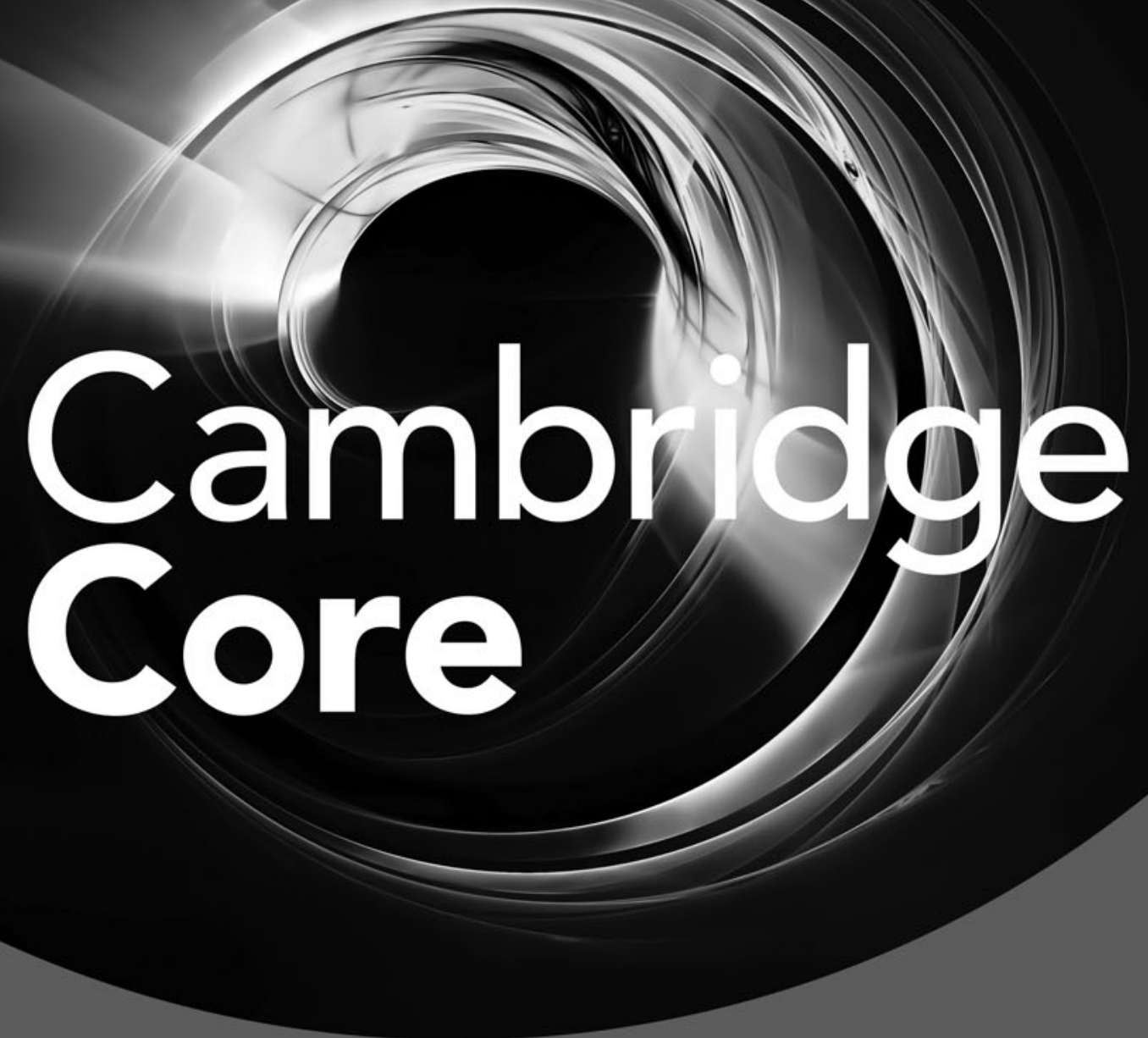

The new home of

Cambridge Journals

cambridge.org/core

Cambridge Core 


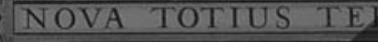

\section{History \\ Books and Journals from Cambridge University Press}

History is the largest single subject area for the Press. It is a programme with both depth and breadth, ranging in subject matter from late antiquity to the present day, international in scope and embracing new approaches.

Our publishing includes major reference series, textbooks and monographs, as well as a collection of distinguished journals affiliated to the world's leading scholarly societies.

Together, they reflect the diversity of the discipline and offer an unmatched resource for today's historians.

For further details visit:

\section{cambridge.org/core-history}

\section{Cambridge core}


The Journal of Chinese History / 中國歷史學刊 publishes research articles, review essays, and book reviews on all periods of Chinese history and all sub-specialties of history-social, cultural, political, economic, and intellectual. The journal aims to keep its readers abreast of important trends in historical scholarship and welcomes inquiries about review essays and special issues on focused topics. Innovative articles of any length will be considered, but there is a preference for articles of broad interest to Chinese historians and ones of moderate length (8,000 to 14,000 words).

\section{Subscription information}

The Journal of Chinese History is published twice a year (January and July) by Cambridge University Press, One Liberty Plaza, New York, NY 10006, USA.

The subscription price of Volume 1 (2017) including delivery by air where appropriate (but excluding VAT), is $\$ 310.00$ ( $\mathrm{f200.00)}$ for institutions print and online; $\$ 280.00$ ( $\mathrm{f} 180.00$ ) for institutions online only.

Orders, which must be accompanied by payment, may be sent to a bookseller, subscription agent or direct to the publisher: Cambridge University Press, Journals Fulfillment Department, One Liberty Plaza, New York, NY, 10006, USA; or Cambridge University Press, UPH, Shaftesbury Road, Cambridge CB2 8RU, England.

For single issues, please contact subscriptions_newyork@cambridge.org.

\section{Advertising}

For information on display ad sizes, rates, and deadlines for copy, please contact USAdSales@cambridge.org.

ISSN: 2059-1632

EISSN: 2059-1640

(C) Cambridge University Press, 2017. All rights reserved.

No part of this publication may be reproduced, in any form or by any means, electronic, photocopying, or otherwise, without permission in writing from Cambridge University Press. Policies, request forms and contacts are available at: http://www.cambridge.org/about-us/rights-permissions

Permission to copy (for users in the U.S.A.) is available from Copyright Clearance Center http://www.copyright.com, email: info@copyright.com.

Postmaster: Send address changes to Journal of Chinese History, Cambridge University Press, One Liberty Plaza, New York, NY 10006, USA. 


\section{journal of CHINESE HISTORY \\ 中國歴史學刊}

\section{Contents}

VOLUME 1 - ISSUE $2 \cdot$ JULY 2017

235 Why Military Institutions Matter for Chinese History circa 600-1800 David Robinson

243 The Reach of the Military: Tang

David A. Graff

269 Military Institutions as a Defining Feature of the Song Dynasty

Peter Lorge

297 Why Military Institutions Matter for Ming History

David Robinson

329 Qing Military Institutions and Their Effects on Government, Economy, and Society, 1640-1800

\section{Yingcong Dai}

353 Review Essays

369 Book Reviews

417 Erratum

419 Corrigendum 